\title{
A harmonização orofacial como uma nova especialidade da odontologia: aspectos
}

\author{
legais \\ Orofacial harmonization as a new specialty in dentistry: legal aspects \\ Armonización orofacial como nueva especialidad en odontología: aspectos legales
}

Recebido: 04/01/2022 | Revisado: 09/01/2022 | Aceito: 16/01/2022 | Publicado: 18/01/2022

\author{
Thaisa Nascimento Ramalho Leite \\ ORCID: https://orcid.org/0000-0002-9054-2326 \\ Centro Universitário UNIESP, Brasil \\ E-mail: nascimentothaisa@yahoo.com.br \\ Lais Guedes Alcoforado de Carvalho \\ ORCID: https://orcid.org/0000-0003-2615-2582 \\ Centro Universitário UNIESP, Brasil \\ E-mail: lais.carvalho@iesp.edu.br \\ Vitor Matheus da Silva Luna \\ ORCID: https://orcid.org/0000-0002-7490-979X \\ Centro Universitário UNIESP, Brasil \\ E-mail: vitormsl.gba@gmail.com \\ Andrê Parente de Sá Barreto Vieira \\ ORCID: https://orcid.org/0000-0001-5523-7599 \\ Centro Universitário UNIESP, Brasil \\ E-mail: andre.barreto@iesp.edu.br
}

\begin{abstract}
Resumo
Numa abordagem descritiva e integrativa este trabalho objetiva verificar o processo evolutivo até a consolidação da Harmonização Orofacial como especialidade reconhecida pelo Conselho Federal de Odontologia. Através da consulta de documentos oficias, artigos e revistas científicas na área da odontologia, pode-se analisar a justificativa que sustenta a nova especialidade através dos referenciais teóricos estabelecidos. Foi possível suscitar o entendimento acerca das lutas travadas entre o Conselho Federal de Odontologia, Conselho Federal de Medicina juntamente com entidades médicas através das leis, resoluções e embates judiciais. Favorecendo uma análise dos aspectos legais envolvidos de 2011 até 2019, ano em que a harmonização orofacial é reconhecida como especialidade da odontologia e, posteriormente, atualizações pertinentes até o ano de 2021. O resultado da resiliência do Conselho Federal de Odontologia diante das dificuldades e das lutas judiciais travadas foi a manutenção de uma resolução tão importante pelos territórios anatômico e científico, conquistados mediante a capacidade e as tendências contemporâneas, dinâmicas e evolutivas com observância do Código de Ética Odontológico.
\end{abstract}

Palavras-chave: Odontologia; Estética; Jurisprudência.

\begin{abstract}
In a descriptive and integrative approach, this work aims to verify the evolutionary process until the consolidation of Orofacial Harmonization as a specialty recommended by the Federal Council of Dentistry. Through the consultation of official documents, as well as the consultation of articles and scientific journals in the field of dentistry, we can analyze a justification that supports a new specialty through the applied theoretical frameworks. We try to raise understanding about the struggles between the Federal Council of Dentistry and the Federal Council of Medicine, associated with medical entities, through laws, rules and judicial procedures. Encourage an analysis of the legal aspects involved from 2011 to 2019, a year in which Orofacial Harmonization is considered a specialty in dentistry. The result of the resilience of the Federal Council of Dentistry in the face of the difficulties and the judicial struggles waged was the maintenance of such an important resolution for anatomical and scientific territories conquered using a capacity and as the contemporary, dynamic and evolutionary trends with observance of the Code of Dental Ethics.
\end{abstract}

Keywords: Dentistry; Esthetics; Jurisprudence.

\section{Resumen}

En un enfoque descriptivo e integrador, este trabajo tiene como objetivo verificar el proceso evolutivo hasta la consolidación de la Armonización Orofacial como especialidad reconocida por el Consejo Federal de Odontología. Mediante la consulta de documentos oficiales, artículos y revistas científicas del campo de la odontología, es posible analizar la justificación que sustenta la nueva especialidad a través de referencias teóricas establecidas. Se logró aumentar el entendimiento sobre las luchas entre el Consejo Federal de Odontología, el Consejo Federal de Medicina y entidades médicas a través de leyes, resoluciones y enfrentamientos legales. Favorecer el análisis de los aspectos 
legales involucrados desde 2011 hasta 2019, año en el que se reconoce la armonización orofacial como especialidad en odontología y, posteriormente, actualizaciones relevantes hasta 2021. Resultado de la resiliencia del Consejo Federal de Odontología ante las dificultades y Las luchas legales que se libraron fue el mantenimiento de tan importante resolución por parte de los territorios anatómicos y científicos, conquistados a través de la capacidad y tendencias contemporáneas, dinámicas y evolutivas, con observancia del Código de Ética Dental.

Palabras clave: Odontología; Estética; Jurisprudencia.

\section{Introdução}

As ciências médicas crescem científica e tecnologicamente nos seus fundamentos e práticas sob legislações e exigências ético-jurídicas que também são dinâmicas. O desenvolvimento científico não se limita às pesquisas sistematizadas de cada ramo do saber, mas depende também da própria evolução do coletivo-social (Cantalice, 2016).

A odontologia se enquadra numa área qualificada da saúde, que reúne as finalidades estética e funcional, necessitando da coexistência dos dois princípios para a harmonia e equilíbrio nos tratamentos (Dall'Magro et al., 2015; Cunha et al., 2016). Ela segue um curso evolutivo natural com renovação constante das técnicas, instrumentais, materiais e metodologias em todas as suas áreas. A Harmonização Orofacial (HOF) surge a partir destas evoluções científicas assim como as demais especialidades odontológicas preexistentes. Dessa forma, a HOF pode inclusive contribuir com as demais áreas visando um trabalho integrado como por exemplo na cirurgia bucomaxilofacial. (Albuquerque et al, 2014; Dall'Magro et al., 2021).

As conexões e avanços da produção científica na área médica são resultantes de pesquisas originais desenvolvidas mediante as limitações terapêuticas, preventivas ou corretivas em face das patologias e disfunções. Na odontologia, os aspectos funcionais podem ser considerados tão relevantes quanto os estéticos (Oliveira Júnior. et al., 2019).

O surgimento das metodologias nas práticas da odontologia, contudo, não tem o reflexo apenas das pesquisas puramente originais, pois as inovações partem das conquistas e conviç̧ões científicas históricas, integrando-se a estudos substanciosos e investigações levadas pela literatura científica às publicações (Peixoto, 2019).

A demanda pelos procedimentos estéticos vem aumentando nos consultórios odontológicos, e o preparo profissional torna-se incontestável para a assistência integral ao paciente, com responsabilidade ética (Acosta et al, 2015).

Assim, a qualificação profissional, nas recentes especializações em harmonização orofacial torna-se imprescindível com necessidade de disciplinas voltadas para a melhoria do atendimento (Santini, 2017).

Conceitos importantes foram agregados à odontologia, como qualidade de vida e bem estar. Seja com o tratamento de patologias específicas nas diversas especialidades odontológicas, ou proporcionando bem estar e estética, possibilitando um sorriso espontâneo a uma pessoa (Barbosa, 2017).

O conhecimento da anatomia, fisiologia, patologia e das ciências afins à formação do cirurgião dentista, capacita o manejo de toda região anatômica da cabeça, ampliando sua área de atuação. Assim, vivemos uma expansão da odontologia também no ramo da estética, com o manejo de técnicas, drogas, materiais e metodologias aplicáveis ao tratamento orofacial (Kobayashi, 2014).

Deste modo, segundo Garbin e Wakayama (2019) com a odontologia contemporânea, na era da supervalorização da estética e dos padrões da anamnese e indicação posológica da medicação voltada à beleza, a busca pelos procedimentos de harmonização orofacial torna-se cada vez mais constante e recorrente nos consultórios.

A harmonização orofacial tem sido reconhecida, em bases científicas através de um processo paulatino de ensino e aprendizagem, visando à reabilitação funcional e estética do sistema estomatognático e estruturas orofaciais de sua área de atuação (Almeida et al, 2010; Ahari Uz et al, 2016).

Este trabalho objetiva ampliar o entendimento acerca do processo evolutivo da odontologia situando o passo atual, portanto este estudo pauta uma revisão contextualizada na discussão e a abrangência da HOF nas extensões odontológicas em face de suas ênfases legais, revisando as lutas e aspectos históricos recentes formadores das práticas odontológicas voltadas aos 
aspectos estéticos.

\section{Metodologia}

Trata-se de um estudo descritivo, caracterizado como uma revisão de literatura narrativa, de caráter reflexivo (Gil, 2019), com o propósito de discutir as implicações ético-legais envolvidas no reconhecimento da harmonização orofacial como especialidade odontológica em detrimento do processo histórico recente.

Conforme Gil (2019) é por meio da pesquisa bibliográfica que o pesquisador faz contato direto com tudo o que foi publicado, dito, filmado ou de alguma outra forma registrado sobre determinado tema. Dessa forma, a presente revisão tem por finalidade reunir e sintetizar documentos, leis e decretos publicados, permitindo delimitar nosso objeto de estudo, que é a abordagem ética da HOF na odontologia. A a análise crítica desenvolvida no presente estudo foi realizada pelos autores após leituras de todos os documentos selecionados, as quais foram realizadas por todos os autores do presente estudo possibilitando a síntese do estado do conhecimento do referido assunto, além de apontar lacunas do conhecimento que precisam ser preenchidas com a realização de novos estudos (Prodanov, 2013).

Para realização da presente revisão de literatura, foram consultados documentos federais oficiais, legislações, decretos e normativas no período de 2011 a 2021, a partir de uma análise crítica e interpretação de tais documentos oficiais que regulamentam e norteiam o exercício da HOF dentro da odontologia. Esses documentos foram analisados sob os aspectos de sua qualidade para a abordagem do método científico a ser aplicando, bem como quanto à relevância, para uma melhor concatenação temporal e do raciocínio integrativo, e quanto ao seu conteúdo para a construção do referencial teórico ligados à casuística da odontologia no Brasil.

Artigos científicos publicados na língua portuguesa também foram consultados, bem como internacionais, para permitir uma análise comparativa com a realidade da especialidade no Brasil, permitindo uma sustentação do referencial teórico e histórico na abordagem do tema relacionado à odontologia e à harmonização orofacial. Ademais, foram excluídos da pesquisa os documentos, leis, decretos e legislações que não se adequaram à temática em questão ou que apenas tratam alguns dos seus aspectos sem a discussão dos resultados em torno do propósito do trabalho.

\section{Resultados e Discussão}

Este trabalho vem ajudar a ampliar o entendimento de um processo cronológico relacionado à HOF, retratando também a história de batalhas sucessivas da odontologia contra entidades médicas consideradas "poderosas". Entre quedas e levantes, as vitórias do Conselho Federal de Odontologia (CFO) foram evidentes e pujantes, à medida que todos os cirurgiõesdentistas (CDs) puderam testemunhar a independência e autonomia da profissão que não está submissa aos interesses particulares das entidades médicas. Portanto, vemos os caminhos da odontologia com otimismo e certeza da qualificação cientifica e ética para atender aos anseios da sociedade.

Observando o que foi levantado junto à literatura, é importante ressaltar a relevância dos aspectos éticos, os critérios teóricos e as práticas abrangidas pelo desenvolvimento da especialização da Harmonização Orofacial (HOF). Contudo o caminho trilhado pela odontologia permanece gerando repercussões intensas na área da saúde até o presente momento.

O início do uso da toxina botulínica pela odontologia pode ser considerado um marco no desponte com projeções à HOF, o que causou impacto chegando a preocupar as entidades médicas, em seguida citadas, que se sentiram ameaçadas com a abertura desse nicho científico e de mercado para a odontologia.

As discussões sobre a área de atuação do cirurgião dentista geraram ressonância onde se travaram disputas judiciais, especialmente pelo Conselho Federal de Medicina (CFM) e outras entidades médicas, a exemplo da Associação Médica Brasileira (AMB), Sociedade Brasileira de Cirurgia Plástica (SBCP) e Sociedade Brasileira de Dermatologia (SBD). Estas com 
argumentos sob a ótica do Ato Médico, Lei $\mathrm{N}^{\circ}$ 12.842, de 10 de Julho de 2013, em seu art. $3^{\circ}$ inciso III que trata da indicação e da execução de procedimentos invasivos, sejam diagnósticos, terapêuticos ou estéticos, incluindo os acessos vasculares profundos, as biópsias e as endoscopias (Brasil, 2013).

Verifica-se a pretensão protecionista do CFM através da implementação da lei federal denominada "Ato Médico" com o objetivo de reservar todos os procedimentos invasivos à exclusividade médica. Apesar de a lei ter sido sancionada, ocorreram vetos importantes, havendo também ressalvas à odontologia que teria autonomia para realizar anestesias e realizar procedimentos invasivos na sua área de atuação. Entretanto o Ato Médico parece uma tentativa de conter os avanços de outras áreas da saúde reservando para a classe médica uma competência científica majoritária.

Paralelamente, é importante ressaltar que no processo histórico da odontologia nos Estados Unidos, que refletiu, consequentemente, no Brasil, verifica-se que a odontologia tem suas raízes na própria medicina, mas que em determinado tempo tornou-se independente. Segundo Martins, Dias e Lima (2018, p.2), "A chegada da era moderna trouxe implicações para a odontologia, a qual se projeta como profissão independente da Medicina, em primeiro lugar, nos Estados Unidos". A relação da medicina com a odontologia deveria ser mais empática, pois são consideradas ciências irmãs, contudo com vieses diferentes, cada uma com suas qualificações e particularidades, mas que se alicerçam numa mesma base, a considerar as disciplinas anatomia, fisiologia, fisiopatologia, farmacologia, bioquímica, patologia entre outras características próprias das duas no campo de trabalho, como por exemplo, a anestesia, a antibioticoterapia, a cirurgia. Recordando o processo histórico podemos entender melhor.

Com o decreto 9.311 de 25 de outubro de 1884, 70 anos após a formalização do curso de medicina, o de odontologia foi reconhecido como curso superior. O decreto 9.311 criou os cursos de odontologia nas faculdades do Rio de Janeiro e da Bahia, anexo ao de medicina, instituindo-se o cargo e preparador de odontologia, como função integrante da cadeira de cirurgia, o curso de odontologia funcionava de forma anexa ao de medicina, tendo como docentes, em sua maioria, médicos e alguns dentistas (Pereira, 2012, pp. 163-164).

Diante da alavancada científica da odontologia com a ampliação das suas margens científicas, em 2017 a AMB, o CFM, a SBCP e a SBD emitiram nota conjunta sob o argumento de visar a qualidade assistencial e segurança da população, dando uma ideia de risco aos procedimentos praticados por cirurgiões dentistas.

"Associação Médica Brasileira" (AMB), Conselho Federal de Medicina (CFM), Sociedade Brasileira de Cirurgia Plástica (SBCP) e Sociedade Brasileira de Dermatologia (SBD) vêm a público se manifestar a respeito da Resolução $\mathrm{n}^{\circ}$ 176/2016, do Conselho Federal de Odontologia - CFO, que autoriza uso indiscriminado da toxina botulínica aos odontólogos.

Completa inexistência de autorização legal para utilização indiscriminada da toxina botulínica pelos dentistas, resultados nefastos de procedimentos estéticos decorrentes da atuação de dentistas além da região buco-maxilo-facial, publicidade tendenciosa e sem controle disseminada em meios de comunicação e ausência de atuação específica de supervisão do CFO em relação a todos esses fatos, mesmo após tentativas de iniciativas administrativas de consenso e demonstrações técnicas, jurídicas e documentais da impropriedade da edição da Resolução CFO n 176/2016, levaram-nos formular presente comunicado e adotar medidas judiciais cabíveis.

Em 22 de março de 2017 AMB e SBCP ingressaram com Ação Civil Pública n 0012537-52.2017.4.01.3400 - TRF1, em desfavor do CFO, onde se buscou a imediata suspensão dos efeitos e consequente anulação da Resolução CFO ${ }^{\circ}$ 176/2016. Em seguida, CFM e SBD também ingressaram na referida ação judicial, para subsidiar o magistrado com informações técnico-jurídicas relativas ao tema e provas dessa atuação irregular, que coloca em risco saúde e vida de nossos pacientes.

Portanto, seguindo linha de trabalho conjunto, harmonioso e colaborativo em prol da defesa das prerrogativas médicas, todas entidades signatárias da presente nota não medirão esforços para adoção desta e outras medidas judiciais e 
extrajudiciais para fazer valer o pensamento dominante junto ao Poder Judiciário brasileiro de que é ilegal aumentar prerrogativas profissionais, por intermédio de resolução administrativa, sendo somente a lei (stricto sensu) diploma legítimo para ampliar o campo de atuação de todas profissões, especialmente da área da saúde.

Finalmente, serve a presente também para desfazer qualquer mal- entendido que possa ter ocorrido em relação à desistência da ação judicial anteriormente proposta. Resta, assim, inequívoco o trabalho institucional conjunto, unido e harmonioso das entidades signatárias em prol da saúde da população, da medicina e do médico. (Associação Médica Brasileira [AMB], Conselho Federal de Medicina [CFM] \& Sociedade Brasileira de Dermatologia [SBD], 2017).

Quando se avalia o conteúdo da nota percebe-se uma atitude protecionista como tentativa de reserva de mercado em detrimento da clientela médica, com receio de perderem uma fatia no nicho da estética, colocando para a sociedade de forma leviana que apenas os médicos estão aptos a realizarem procedimentos mais complexos. Por outro lado, vemos que a odontologia desponta na corrida científica nos ramos da anatomia, da fisiologia, da tecnologia de biomateriais e ciências afins demonstrando sua qualificação e competência para atuarem com segurança e ética na usa área de atuação.

Com a Resolução CFO nº 198/19 que reconhece a HOF como especialidade odontológica, dispõe sobre os critérios para a formação profissional na especialidade, amplia a área anatômica de atuação do cirurgião-dentista citando alguns dos biomateriais indutores de colégeno, toxina botulínica, os preenchedores faciais e agregados leucoplaquetários autólogos, fala sobre a intradermoterapia e o uso de indutores percutâneos, nos terços inferior, médio e superior. Além de procedimentos biofotônicos e/ou laserterapia, desde que na sua área de atuação, e em estruturas anexas e afins. Permite também realizar tratamento de lipoplastia facial, por técnicas químicas, físicas ou mecânicas na região orofacial, a técnica cirúrgica de remoção do corpo adiposo de Bichat e técnicas cirúrgicas para a correção dos lábios, liplifting, na sua área de atuação e em estruturas relacionadas anexas e afins (Conselho Federal de Odontologia [CFO], 2019).

Em 2019, em função da Resolução CFO198/2019, outra nota conjunta é emitida, desta vez pela AMB e CFM, repudiando e informando que tomariam as medidas cabíveis para que atos médicos sejam praticados apenas por quem tem formação em Medicina (Brasil, 2019). Em 29 de janeiro de 2019 foi editada a Resolução no 198/2019 pelo Conselho Federal de Odontologia, que reconhece a harmonização orofacial como especialidade odontológica. Os termos de tal resolução supostamente permitem aos dentistas a utilização de toxina botulínica e preenchedores faciais na região orofacial e em estruturas anexas, bem como a realização de procedimentos com vistas a "harmonizar os terços superior, médio e inferior da face".

Neste cenário, verifica-se que ao longo do tempo o avanço das práticas tradicionais vinculadas à funcionalidade e à estética odontológica. Por exemplo, a indicação terapêutica considerada em amplo espectro de substâncias como as toxinas botulínicas tipo A, os ácidos hialurônicos, outros biomateriais e técnicas baseados em padrões científicos vigentes, atuais e em evolução.

Dessa forma, considera-se como início das batalhas entre as entidades médica e o CFO, o uso a toxina botulínica do tipo A, produzida pelo bacilo anaeróbio Clostridium botulinium. Sua introdução na medicina foi direcionada ao tratamento do estrabismo, posteriormente após a anuência e outorga da Agência Nacional de Vigilância Sanitária (ANVISA) no ano 2000 e somente dois anos depois pela Food and Drug Administration foi ampliado o seu uso às outras defecções, incluindo também a odontológica (Dalmedico et al., 2016; Esteves et al., 2016). Nesse contexto, houve um uso gradativo da toxina botulínica na odontologia a exemplo do uso terapêutico nos casos de bruxismo.

As investigações com aprovação científica para o uso da toxina botulínica, também com aplicabilidade na odontologia, estão relacionados aos casos de bruxismo, disfunção temporormandibular (DTM), sorriso gengival, pósoperatório cirúrgico, hipertrofia do músculo masseter, assimetria facial, estética facial, cefaleias e redução salivar em pacientes com Esclerose Lateral Amiotrófica (ELA) (Hamilton \& Burgess, 2010; Jacometti et al., 2017). 
Em relação aos efeitos adversos do uso da toxina botulínica, geralmente ocorrem devido aos erros de dosagem, pontos anatômicos imprecisos e o não seguimento do protocolo clínico. Os efeitos são transitórios, podendo comprometer a expressão facial do indivíduo (Jacovella, 2008; Kammann \& Quiros, 2013).

Aqui se assemelha as argumentações de algumas entidades médicas numa tentativa de minimizar a capacidade do CD, tentando expor imperícia e falta de conhecimento para tratar complicações clínicas oriundas de procedimentos, contudo a odontologia tem fundamentos sólidos metodológicos e científicos que são chancelados pelas disciplinas curriculares com ênfase na anatomia, fisiologia, patologia, fisiopatologia e farmacologia, além de outras que no conjunto tornam o CD apto a tratar as possíveis complicações decorrentes de procedimentos.

No ano de 2011 com a publicação da Resolução CFO 112/14, levou a proibição do uso do ácido hialurônico e restringiu o uso da toxina botulínica para fins exclusivamente estéticos, mas a autorizou para fins terapêuticos exclusivamente odontológicos (CFO, 2011). Posteriormente esta foi alterada pela Resolução CFO-146/15, de 27/03/2014, publicada no D.O.U., Seção 1, página 174, em 14/04/2014, passa a ter vigência com a redação em seu art. $2^{\circ}$, permitindo o uso da toxina botulínica para procedimentos odontológicos e vedado para fins não odontológicos (Brasil, 2014). Neste momento com a contextualização do uso da toxina botulínica para finalidade restrita à ordem odontológica, as principais indicações estão relacionadas no equilíbrio morfofuncional do sistema estomatognático e no controle de dores (Gatto et al., 2019; Haddad et al., 2015).

Contudo, com a evolução da profissão e conhecimento nesta área, a resolução nº176/2016 do Conselho Federal de Odontologia, determina: Art. $1^{\circ}$ - Autorizar a utilização da toxina botulínica e dos preenchedores faciais pelo cirurgiãodentista, para fins terapêuticos funcionais e/ou estéticos, desde que não extrapole sua área anatômica de atuação (CFO, 2016). Esta mesma resolução também define em seus artigos a área de atuação, representada por: superiormente ao osso hioide, até o limite do ponto násio (ossos próprios de nariz) e anteriormente ao trágus, abrangendo estruturas anexas e afins. Além de permitir a realização de procedimentos não cirúrgicos direcionados à HOF no terço superior da face (CFO, 2016, p.3).

A partir desta resolução, fica estabelecida e autorizada a atuação do cirurgião-dentista no terço superior da face, permitindo assim, realização de procedimentos estéticos nesta área, que até então não era possível. Dessa forma, verificou-se o aumento considerável na procura por procedimentos estéticos realizados na odontologia, em especial o uso da toxina do terço superior da face, fortalecendo a inserção do CD nesta área.

As linhas faciais de rugas dinâmicas causadas por contrações repetitivas da musculatura facial e pelo envelhecimento da pele podem ser amenizadas com a Toxina Botulínica Tipo A, já bem estabelecida na literatura científica com eficácia em aplicações estéticas terapêuticas, preventivas e corretivas, não cirúrgicas, com relação a essas linhas faciais, agindo por intermédio de um mecanismo de ação bastante eficiente, minimamente invasiva e com benefícios reais (Ribeiro et al., 2014). Dessa forma, a partir da resolução n$^{\circ} 176 / 2016$ do CFO, o cirurgião-dentista torna-se um profissional apto a atuar em área estética e funcional da face, permitindo maior área de atuação.

Em 16 de dezembro de 2017, a pedido da SBCP, a justiça federal concede a liminar de suspensão da resolução do CFO n¹76/2016, que habilitava os cirurgiões-dentistas a utilizarem a toxina botulínica e preenchedores faciais (Brasil, 2017). Esse fato inegavelmente se deu pela ascensão da odontologia nesta área, indo contra os interesses das entidades médicas SBPC e SBD até então "detentoras" das técnicas estéticas e dos seus respectivos nichos de clientelas.

No dia, 06 de novembro de 2018, o Conselho Regional de Odontologia do Piaú - CRO PI, publica no seu website oficial referindo vitória do CFO com a extinção do processo judicial proibitório aos cirurgiões-dentistas a aplicação da toxina botulínica para finalidade estética, voltando à resolução do CFO nº176/2016, a ter validade no território brasileiro (CRO, 2018).

Por fim, mantém-se o fruto da luta do CFO com a vigência da resolução 198/2019, verificamos em: 
O Presidente do Conselho Federal de Odontologia, no uso de suas atribuições legais e regimentais, "ad referendum" do Plenário.

Considerando o que dispõe o art. $6^{\circ}$, caput e incisos I e VI da Lei ${ }^{\circ}$ 5081, de 24 de agosto de 1966, que regula o exercício da Odontologia, bem como o art. $4^{\circ}, \S 6^{\circ}$ da Lei $n^{\circ} 12.842$ de 10 de julho de 2013, que regula o exercício da medicina;

Considerando que o Código de Ética Odontológica dispõe que a Odontologia é uma profissão que se exerce em benefício da saúde do ser humano e da coletividade sem discriminação de qualquer forma ou pretexto e que é dever do cirurgião-dentista manter atualizados os conhecimentos profissionais técnicos, científicos e culturais necessários ao pleno desempenho do exercício profissional; e,

Considerando, ainda, a necessidade de regulamentar essa especialidade, em virtude da já existência de cursos de pósgraduação autorizados pelo MEC, em instituições de ensino superior, com o objetivo formar cirurgiões-dentistas especialistas em harmonização orofacial: RESOLVE:

Art. $1^{\circ}$. Reconhecer a Harmonização Orofacial como especialidade odontológica.

Art. $2^{\circ}$. Definir a Harmonização Orofacial como sendo um conjunto de procedimentos realizados pelo cirurgiãodentista em sua área de atuação, responsáveis pelo equilíbrio estético e funcional da face. (CFO, 2019. p 1)

Neste cenário, ressaltamos que a Resolução CFO-218, de 18 de dezembro de 2019 regulamenta o exercício da Odontologia em estabelecimentos diversos do consultório odontológico dá outras diretrizes, revogando a Resolução CFO212/2019 que tratava a questão com uma menor delimitação estando, portanto, os CDs sujeitos às obrigações legais e éticas neste sentido alinhadas com as determinações da ANVISA (CFO, 2019).

Ademais, a Resolução CFO-230, de 14 de agosto de 2020, regulamenta o artigo 3º da Resolução CFO-198/2019 e tem o intuito de regulamentar, definir critérios e estabelecer os limites da atuação do cirurgião-dentista em Harmonização Orofacial, resolveu que

Art. $1^{\circ}$. Fica vedado ao cirurgião-dentista a realização dos seguintes procedimentos cirúrgicos na face:
a) Alectomia;
b) Blefaroplastia;
c) Cirurgia de castanhares ou lifting de sobrancelhas;
d) Otoplastia;
e) Rinoplastia; e,
f) Ritidoplastia ou Face Lifting.

Art. $2^{\circ}$. Fica vedado também ao cirurgião-dentista a realização de publicidade e propaganda de procedimentos não odontológicos e alheios à formação superior em Odontologia, a exemplo de:
a) Micro pigmentação de sobrancelhas e lábios;
b) Maquiagem definitiva;
c) Design de sobrancelhas;
d) Remoção de tatuagens faciais e de pescoço;
e) Rejuvenescimento de colo e mãos; e,
f) Tratamento de calvície e outras aplicações capilares.

Art. $3^{\circ}$. Fica vedado ao cirurgião-dentista a realização de procedimentos em áreas anatômicas diversas de cabeça e pescoço. (CFO, 2020).

Neste cenário, ressaltamos que a Resolução CFO-230 consegue estabelecer limites éticos e legais acerca da atuação do cirurgião-dentista dentro dos consultórios e na área acadêmica, sendo assim, capaz de unificar e solidificar a Resolução CFO-198.

Em reação a Resolução CFO-230 a SBD publicou em seu site oficial um texto em características de notícia onde 
consta, dentre outras críticas a Resolução 198/2019/CFO, esclarecimentos a respeito da Resolução 230/2020/CFO: "Não entendemos nessa decisão uma vitória, porque na verdade apenas reitera aquilo que a Lei do Ato Médico". (SBD, 2020).

A figura (Figura 1) abaixo mostra, simbolicamente, uma linha do tempo evidenciando as Resoluções do CFO e as reações das entidades médicas com protocolos de medidas judiciais, liminares, e extinção de processos, além das notas de repúdio emitidas relativas às Resoluções do CFO.

Figura 1. Esquema identificando a evolução histórica da Harmonização Orofacial na Odontologia.

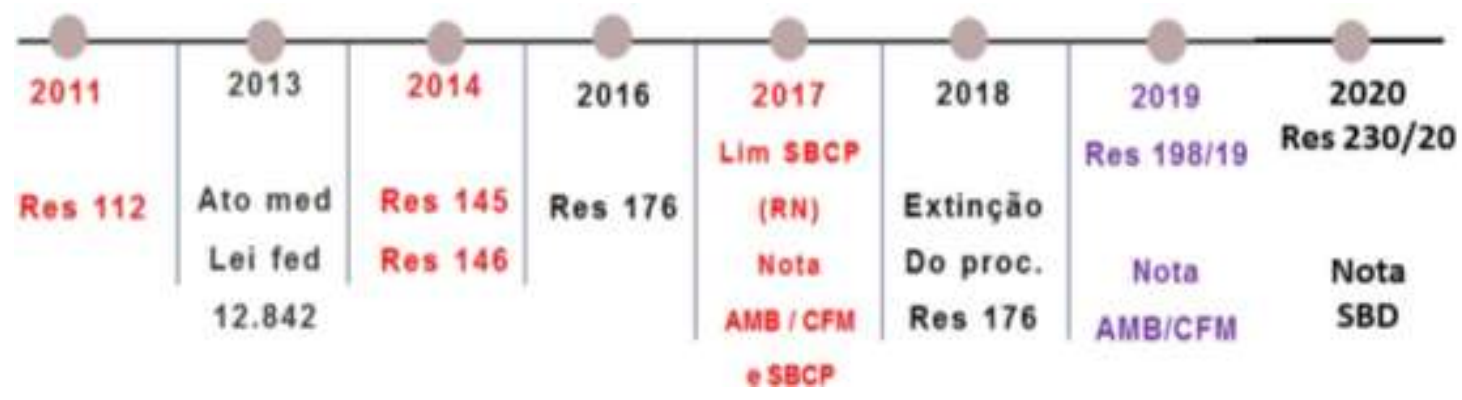

Fonte: Autores.

Assim, após as várias lutas travadas desde o ano de 2011 até os dias atuais, o CFO e os CRO's juntamente com todos os CD’s do Brasil, vivenciaram uma vitória não apenas no campo judicial, mas também ideológico libertando a odontologia brasileira de uma sombra que parecia emperrar o seu desenvolvimento científico e profissional, com força e determinação demonstrando que não estamos sob julgo, do ponto de vista científico e tecnológico, diferente da medicina ou de qualquer outra ciência.

\section{Considerações Finais}

O resultado da resiliência do Conselho Federal de Odontologia (CFO) diante das dificuldades e das lutas judiciais travadas foi a manutenção de uma resolução tão importante, não no sentido de a Harmonização Orofacial ser uma especialidade da odontologia mais ou menos importante que as outras, mas pelos territórios anatômico e científico conquistados mediante a capacidade e as tendências contemporâneas, dinâmicas e evolutivas de uma profissão com firmezas científica e ética bem estabelecidas.

Enfatiza-se, ainda, que se faz necessário os CDs respeitarem e cumprirem as normativas e regimentos do Código de Ética Odontológico, para que realizem um trabalho seguro e com respaldo legal. Dentro dessa perspectiva, são necessários mais estudos futuros que possam avaliar o cumprimento das normativas éticas e legais pelos CDs especialistas em harmonização orofacial.

\section{Referências}

Acosta, R. T., Kelmer, F., Oliveira, R. C. G., \& Oliveira, R. C. G. (2015). Uso da toxina botulínica como meio terapêutico para tratamento de assimetria facial causada por hipertrofia do músculo masséter. Revista UNINGÁ Review, 21(1).

Ahari, U. Z., Eslami, H., Falsafi, P., Bahramian, A., \& Maleki, S. (2016). The buccal fat pad: Importance and function. J Dent Med Sci, 15(6), 79-81.

Albuquerque, M. R., Peixoto, A. P \& Vieira, J. B. (2014) Especialidades odontológicas. Saberes científicos.

Almeida, M. D. D., Farias, A. C. R., \& Bittencourt, M. A. V. (2010). Influência do posicionamento sagital mandibular na estética facial. Dental Press Journal of Orthodontics, 15, 87-96.

Rezende, M. C. R. A., \& Fajardo, R. S. (2016). Abordagem estética na Odontologia. Archives of Health Investigation, 5(1). 
Antunes, J. S., Karvat, J., Aragão, F. A., \& Bertolini, G. R. F. (2015). Laser De Baixa Potência, No Espectro De Luz Vermelha, Em Lesão Nervosa Periférica: Revisão Sistemática. Revista Pesquisa em Fisioterapia, 5(1).

BARBOSA, A. J. (2017). Saúde bucal e programas de assistência integral as clientelas vulneráveis. Campello.

Bass, L. S., Smith, S; Busso, M \& McCkaren, M. (2010). Hidroxilapatite de cálcio (Radiesse) para o tratamento de dobras nasolabiais: resultados de segurança e eficácia a longo prazo. AesthetSurg J, 30(2).

Lei $N^{o} 12.842$ de 10 de Julho de 2013. Dispõe sobre o exercício da Medicina. http://www.planalto.gov.br/ccivil_03/_Ato2011-2014/2013/Lei/L12842.htm.

Conselho Federal de Odontologia. (2011). Resolução $\quad$ CFO $N^{\mathrm{o}} \quad 112, \quad$ de $02 \quad$ de $\quad$ setembro de 2011. http://sistemas.cfo.org.br/visualizar/atos/RESOLU\%c3\%87\%c3\%83O/SEC/2011/112.

Conselho Federal de Odontologia. (2014). Resolução $\quad$ CFO $N^{o} \quad 146$, de $16 \quad$ de $\quad$ abril de 2014. http://sistemas.cfo.org.br/visualizar/atos/RESOLU\%c3\%87\%c3\%83O/SEC/2014/146.

Conselho Federal de Odontologia. (2016). Resolução CFO $N^{o}$ 176, de 6 de setembro de 2016. Rio de Janeiro, 06 de set. De 2016. http://sistemas.cfo.org.br/visualizar/atos/RESOLU\%c3\%87\%c3\%83O/SEC/2016/176.

Conselho Federal de Medicina. (2017). CFM e entidades médicas se posicionam contra resolução da odontologia, 2017. Recuperado em: https://portal.cfm.org.br/index.php?option=com_content\&view=article\&id=26830:2017 -04-01-16-37-06\&catid=3.

Conselho Federal de Medicina. (2017). Processo No 0809799-82/2017.4.058400, 2017. https://portal.cfm.org.br/images/stories/pdf/20171215150152.pdf

Conselho Federal de Odontologia (2019). Resolução CFO $N^{o}$ 198, de 29 de janeiro de 2019. Rio de Janeiro, 29 de jan. de 2019. http://sistemas.cfo.org.br/visualizar/atos/RESOLU\%C3\%87\%C3\%83O/SEC/2019/198.

Conselho Federal de Medicina (2019). Nota Conjunta da AMB e CFM sobre a Resolução no 198/2019 do Conselho Federal de Odontologia, 2019. Recuperado em: http://portal.cfm.org.br/index.php?option=com_content\&view=article\&id=28063

Conselho Federal de Odontologia. Resolução $C F O N^{o}$ 218, de 18 de dezembro de 2019. Rio de Janeiro, 18 de dez. de 2019. http://transparencia.cfo.org.br/atonormativo/?id=3226.

Conselho Federal de Odontologia. Resolução CFO $N^{o}$ 230, de 14 de agosto de 2020 . Brasília, 14 de Ago. de 2020 . https://site.crosp.org.br/uploads/arquivo/625e775b09adff84e9ca7e26b1916298.pdf.

Cantalice, J. J. (2016). Ciência e tecnologia: avanços da Odontologia aplicada. Editorial Sepúlveda.

Cavalcanti, A. N., Azevedo, J. F., \& Mathias, P. (2017). Harmonização Orofacial: a Odontologia além do sorriso. Journal of Dentistry \& Public Health, 8(2), 35-36.

Conselho Regional de Odontologia. (2018). Aplicação de toxina botulínica: Decisão da Justiça. Piauí. http://www.cropi.org.br/noticias/aplicaacaao-de-toxinabutolinica-decisaao-da-justiaca-ae-vitaoria-de-toda-a-classe-odontolaogica-do-paais-afirma-presidente-do-cfo-823.html.

Crocco, E. I., Alves, R. O., \& Alessi, C. (2012). Eventos adversos do ácido hialurônico injetável. Surgical \& Cosmetic Dermatology, 4(3), 259 -263.

DaCunha, M. G., Daza, F., Rezende, F. C., \& Machado Filho, C. D. A. (2016). Aplicação de ácido poli-1-lático para o tratamento da flacidez corporal. Surgical \& Cosmetic Dermatology, 8(4), 322-327.

Dall'Magro, A. K., Santos, R. D., Dall'Magro, E., Fior, B., Matiello, C. N., \& Carli, J. P. D. (2015). Aplicações da toxina botulínica em odontologia. Salusvita, 34(2), 371-382.

Dall'Magro, A. K., Dogenski, L. C., Dall'Magro, E., Figur, N. S., Trentin, M. S., \& De Carli, J. P. (2021). Orthognathic surgery and orthodontics associated with orofacial harmonization: Case report. International journal of surgery case reports, 83, 106013. https://doi.org/10.1016/j.ijscr.2021.106013

Dalmedico, M. M., Meier, M. J., Felix, J. V. C., Pott, F. S., Petz, F. D. F. C., \& Santos, M. C. (2016). Hyaluronic acid covers in burn treatment: a systematic review. Revista da Escola de Enfermagem da USP, 50, 0522-0528.

Esteves, A. L. V., Pires, F. R., Miranda, Á. M. M. A., Amaral, S. M., \& Netto, J. D. N. S. (2016). Reação de corpo estranho a material de preenchimento estético: relato de quatro casos. Revista Brasileira de Odontologia, 73(4), 344.

Eustachio, R. R., Veronesi, G. F., Damante, C. A., Sant'Ana, A. C. P., Rezende, M. L. R. de, \& Zangrando, M. S. R. (2017). Regeneração de defeito periodontal vertical com associação de ácido hialurônico. Journal of Applied Oral Science. Bauru.

Faria, C., Dias, R., Campos, A., Daher, J., Costa, R., \& Barcelos, L. (2001). Bichectomy and its contribution to facial harmony. Revista Brasileira de Cirurgia Plástica, 33(4), 446-452.

Garbin, A. J. I., Wakayama, B., Saliba, T. A., \& Garbin, C. A. S. (2019). Harmonização orofacial e suas implicações na odontologia. Braz. J. Surg. Clin. Res, 27(2), 116-122.

Gatto, R. C. J., Garbin, A. J. Í., Corrente, J. E., \& Garbin, C. A. S. (2019). The relationship between oral health-related quality of life, the need for orthodontic treatment and bullying, among Brazilian teenagers. Dental press journal of orthodontics, 24, 73-80.

Gil, A. C. (2008). Métodos e técnicas de pesquisa social. (6a ed.), Editora Atlas SA.

Haddad, A., Kadunc, B. V., Guarnieri, C., Noviello, J. S., da Cunha, M. G., \& Parada, M. B. (2017). Conceitos atuais no uso do ácido poli-1-láctico para rejuvenescimento facial: revisão e aspectos práticos. Surgical \& Cosmetic Dermatology, 9(1), 60-71. 
Research, Society and Development, v. 11, n. 2, e7811225357, 2022

(CC BY 4.0) | ISSN 2525-3409 | DOI: http://dx.doi.org/10.33448/rsd-v11i2.25357

Hamilton, T. K., \& Burgess, C. M. (2010). Considerations for the use of injectable poly-L-lactic acid in people of color. Journal of drugs in dermatology: $J D D, 9(5), 451-456$.

Jacovella, P. F. (2008). Use of calcium hydroxylapatite (Radiesse®) for facial augmentation. Clinical interventions in aging, 3(1), 161.

Kammann, M. A., \& Quirós, O. (2013). Análisis facial en ortodoncia interceptiva. Revista latinoamericana de Ortodoncia y Odontopediatria, 1.

Kobayashi, T. K. (2014). Aspectos éticos e legais da evolução das especializações em Odontologia. Providencial.

Martins Y. V. M, Dias, J. N, \& Lima, I. P. C. (2018). A evolução da prática odontológica brasileira: Revisão de literatura. Revista de Ciências da Saúde Nova Esperança, 16(3), 83-90.

Peixoto, L. M. O. (2019). Metodologia terapêutica em Odontologia Corretiva e Estética facial. Pesquisa de campo em pacientes vulneráveis. Texto Integral, 2019

Pereira, W. (2012). Uma história da Odontologia no Brasil. Revista História \& Perspectivas, 25(47).

Prodanov, C. C., \& De Freitas, E. C. (2013). Metodologia do trabalho científico: métodos e técnicas da pesquisa e do trabalho acadêmico. (2a ed.). Editora Feevale.

Oliveira Júnior, S. V. Ramalho, D., \& Carvalho, O. P. L. A. Estudos científicos de aprimoramento da odontologia estética. TCC Integral. Feitosa edições Ltda.

Ramos, D. A. N. (2018). Casuística clínica das especializações odontológicas. Integral.

Ribeiro, I. N. D. S., de Oliveira Santos, A. C., Gonçalves, V. M., \& da Cruz, E. F. (2014). O uso da toxina botulínica tipo "A" nas rugas dinâmicas do terço superior da face. Revista da Universidade Ibirapuera.

Santini, L. P. (2017). Evolução da Odontologia através da multiplicação das especializações. Universal. 